\title{
An Assessment of Factors Influencing Forest Harvesting in Smallholder Tobacco Production in Hurungwe District, Zimbabwe: An Application of Binary Logistic Regression Model
}

\author{
Chipo Chivuraise, ${ }^{1}$ Tafireyi Chamboko, ${ }^{1}$ and Godfrey Chagwiza ${ }^{2}$ \\ ${ }^{1}$ Department of Agricultural Economics \& Extension, University of Zimbabwe, P.O. Box MP167, Mount Pleasant, Harare, Zimbabwe \\ ${ }^{2}$ Department of Applied Mathematics, National University of Science \& Technology, P.O. Box AC939, Ascot, Bulawayo, Zimbabwe \\ Correspondence should be addressed to Chipo Chivuraise; cchivuraise@yahoo.com
}

Received 16 October 2015; Revised 29 December 2015; Accepted 6 January 2016

Academic Editor: Tibor Janda

Copyright (C) 2016 Chipo Chivuraise et al. This is an open access article distributed under the Creative Commons Attribution License, which permits unrestricted use, distribution, and reproduction in any medium, provided the original work is properly cited.

\begin{abstract}
Deforestation is one of the major effects posed by the smallholder tobacco farming as the farmers heavily depend on firewood sourced from natural forest for curing tobacco. The research aims at assessing the factors that influence the harvesting of natural forest in the production of tobacco. Data is collected through the structured questionnaire from 60 randomly selected farmers. Binary logistic regression model is used to explain the significance of factors influencing natural forest harvesting. Results show that farmer experience, tobacco selling price, and agricultural training level negatively affect the harvesting of natural forests (to obtain firewood) for curing tobacco significantly $(p<0.05)$. However, gender, size of the household, tobacco yield, and level of education are insignificant $(p>0.05)$ in influencing natural forest harvesting. Though farmers are exploiting the environment and at the same time increasing foreign currency earning through tobacco production, there is therefore a need to put in place policies that encourage sustainable forest product utilization such as gum plantations, subsidizing price of coal, and introducing fees, as well as penalties or taxes to the offenders.
\end{abstract}

\section{Introduction}

The Sub-Saharan African region is one of the poorest parts of the world in terms of economy and as such heavily depends on agriculture for employment and income generation to sustain itself [1]. Agriculture is the backbone of most economies particularly the developing countries as it is the major source of revenue [2]. In the wake of increased environmental and sustainability concerns with improvement in agricultural production, countries are faced with the dilemma of choices in resource allocation and use especially in agriculture. Short-run technological gains and long-run environmental conservation are the two choices concerned in sustainable development. These require the adoption of appropriate technology that would suit particular levels of different global communities. There is need to optimize the use of scarce resources in the management of natural resources to obtain the best return from the environment. Agriculture and other economic activities are producing externalities that affect the environment such as deforestation and pollution [3].

Zimbabwe heavily depends on agriculture for economic development. Tobacco is a strategic crop in Zimbabwe as it provides employment and foreign currency and also improves the livelihoods of the farmers and the nation at large. One of the major problems in the third world countries is the issue of the environment [4]. Human activities have been viewed as one of the major sources of the environmental degradation. Ibimilua [5] supported that deforestation is caused by human induced activities. Hassan and Hertzler [6] postulated that overgrazing, the extensive removal of tree cover for dry-land farming (both mechanized and traditional), and the excessive cutting of wood resources for fuel purposes are the main causes of deforestation in arid and semiarid environments. 
The World Bank [7] highlighted that more than $50 \%$ of the wood stock removed annually is burnt for energy in central and East African countries. In addition, the cost of tobacco cultivation has been summarized by Lightwood et al. [8] to include, among others, environmental damage such as soil degradation, deforestation, and water pollution. In Tanzania, tobacco is the most driving force of land use changes [9]. Smallholder farmers mainly use natural forest as the source of firewood for tobacco curing because it is cheap to access and this has resulted in deforestation. Wood has been regarded in most of Sub-Saharan Africa as a free good [10]. Deforestation is one of the major impacts caused by the production of tobacco [11]. It is, therefore, important to consider such impacts if tobacco production is to be sustainable.

In addition, deforestation is a particular challenge in the tropical region. This is because the world forests are very important to sustain the environment and human life [12]. The forests are used for both timber and nontimber values [5]. However, if measures are not put in place the benefits may not be realised. On the other hand, environmental degradation in the form of forest loss and soil loss due to mining continues at unprecedented rates in the country, eroding biodiversity and prospects for sustainable economic development of agricultural and forest resources [13].

The farmers should focus on how to reduce deforestation which is the environmental problem at hand. The challenge faced by the smallholder farmers is the development of measures or strategies to maximise use of natural resources while minimizing the effect of resource degradation. The alternative to enhance sustainable development is the conservation of forests, habitats, and biodiversity to increase the productivity and efficiency of natural resource utilization in the different agricultural production activities. It may be difficult to assess exactly how much wood is needed for curing tobacco, but Madeley [14] found out that it takes as much as three hectares of trees to cure one hectare of tobacco in some countries. Therefore, it is of importance for Zimbabwe to tackle this deforestation problem given the long-term impact of it on the local livelihoods.

It is, therefore, important to consider sustainable environmental policies so that measures are put in place to curb deforestation. Chipika and Kowero [15] postulated that the cropland expansion was due to policies put in place to increase cash crop production of maize and cotton. Agriculture has been noted as the major cause of forest loss, having been estimated to account for 90 percent of all deforestation in the tropics [4]. It is also important to consider penalties or taxes such as Pigouvian tax to protect the environment [16]. The key issue is to produce tobacco at an environmentally friendly manner for economic development. African states emphasize development interest and ignore issues of environmental consequences as a result of agricultural production [3]. Environmental problems caused by farming are a direct result of an increasingly intensive and specialized agriculture [17].

The remainder of the paper is arranged as follows. In Section 2, the method used in this study is presented and Section 3 presents findings of the study. In Section 4, conclusions and recommendations are outlined.

\section{Methodology}

The survey was carried out in Hurungwe District which falls under Mashonaland West province of Zimbabwe and lies in natural region $I I b$. This natural region is characterised by an annual rainfall ranging from 900 to $1200 \mathrm{~mm}$. It is located in the northern part of Zimbabwe and is approximately $210 \mathrm{~km}$ west of Harare. The soil types in this district vary from clay loam to black clay soils where the production of the following crops are suitable: maize, soya beans, groundnuts, cotton, tobacco, sugar beans, sunflower, and paprika. In terms of the vegetation, it is a typical miombo, dominated by Brachystegia species and Julbernardia species.

The area constitutes both A1 (newly resettled farmers with land size ranging between 1 and 20 hectares) and communal farmers who are actively participating in tobacco production. Data were collected through a structured questionnaire from 60 randomly selected farmers. Data collected provided the following information: farmers demographic data, land area under tobacco, period into tobacco production, measures done by farmers to ensure they guard against deforestation, methods of tobacco curing, factors influencing tobacco production, challenges in tobacco production, and other questions related to tobacco production and the environment.

Binary logistic regression model was used to explain the significance of the identified factors influencing forest harvesting in the production of tobacco. The following factors were identified: farmer experience $\left(x_{1}\right)$, tobacco selling price $\left(x_{2}\right)$, agricultural training educational level $\left(x_{3}\right)$, gender $\left(x_{4}\right)$, size of the household $\left(x_{5}\right)$, tobacco yield $\left(x_{6}\right)$, and level of education other than agricultural training $\left(x_{7}\right)$. The model is as follows:

$$
\pi_{i}=\operatorname{Pr}\left(Y_{i}=1 \mid X_{i}=x_{i}\right)=\frac{\exp \left(\beta_{0}+\beta_{1} x_{i}\right)}{1+\exp \left(\beta_{0}+\beta_{1} x_{i}\right)} .
$$

Equation (2) is the simplification of (1):

$$
\begin{aligned}
\operatorname{logit}\left(\pi_{i}\right) & =\log \left(\frac{\pi_{i}}{1-\pi_{i}}\right)=\beta_{0}+\beta_{1} x_{i} \\
& =\beta_{0}+\beta_{1} x_{i 1}+\cdots+\beta_{k} x_{i k}
\end{aligned}
$$

where $Y$ is a binary response variable, $Y_{i}=1$ if the trait is present in observation $i, Y_{i}=0$ if the trait is not present in observation $i$, and $X=\left(X_{1}, X_{2}, \ldots, X_{k}\right)$ is a set of explanatory variables and can be discrete, continuous, or a combination. The observed value of the explanatory variables for observation $i$ is denoted by $x_{i}$.

\section{Results and Discussion}

Among the smallholder farmers interviewed, 18\% were communal and $82 \%$ were A1 because the population in the area is dominated by A1 type farmers (see Table 1). Furthermore, most of the interviewed farmers were the head of household $(\mathrm{HOH})(89 \%)$ and the remainder were either wives or sons. Male headed household dominated in this district with $96 \%$ and the remainder were female (who are widows). 
TABLE 1: Information of smallholder tobacco farmers interviewed.

\begin{tabular}{|c|c|c|c|c|}
\hline & & Communal (\%) & $\mathrm{A} 1(\%)$ & Total (\%) \\
\hline Type of farmer & & 18 & 82 & 100 \\
\hline \multirow{2}{*}{ Head of household $(\mathrm{HoH})$} & No & 8 & 3 & 11 \\
\hline & Yes & 10 & 79 & 89 \\
\hline \multirow{2}{*}{ Sex of the $\mathrm{HOH}$} & Male & 18 & 78 & 96 \\
\hline & Female & 0 & 4 & 4 \\
\hline \multirow{2}{*}{ Level of education } & Primary & 10 & 42 & 52 \\
\hline & Secondary & 8 & 40 & 48 \\
\hline \multirow{3}{*}{ Level of agric. training } & Master farmer & 7 & 32 & 39 \\
\hline & Farm experience & 6 & 33 & 39 \\
\hline & None & 5 & 17 & 22 \\
\hline \multirow{3}{*}{ Size of the household } & 1-3 members & 3 & 10 & 13 \\
\hline & 4-6 members & 10 & 52 & 62 \\
\hline & Above 6 members & 5 & 20 & 25 \\
\hline Total number of farmers int & & 18.3 & 81.7 & 100 \\
\hline
\end{tabular}

TABle 2: Distribution of tree species used for tobacco curing in Hurungwe District.

\begin{tabular}{lc}
\hline $\begin{array}{l}\text { Tree species } \\
\begin{array}{l}\text { Julbernardia globiflora only } \\
\text { Brachystegia boehmii/spiciformis } \\
\text { only }\end{array}\end{array}$ & $\begin{array}{c}\text { \% farmers using } \\
\text { the tree species }\end{array}$ \\
$\begin{array}{l}\text { Julbernardia globiflora and } \\
\text { Brachystegia boehmii/spiciformis (a } \\
\text { combination) }\end{array}$ & 23 \\
\hline
\end{tabular}

All the farmers interviewed were educated with 52\% having attained primary education and $48 \%$ attained secondary education training. In addition, $39 \%$ of the farmers completed the master farmer training that is offered by Agricultural, Technical, and Extension Services (AGRITEX), another 39\% use the experience they obtain in farms where they were previously working, and $22 \%$ of the farmers were not agriculturally trained. Most of the farmers spend most of their time on their farms practicing agriculture. The household size ranges between 1-3 and $>6$. The members of the family in a household are the source of labour in tobacco production. However, the dominant household size is 4-6 people per household (62\%) followed by $>6(25 \%)$. Farmers heavily depend on family members as the source of labour and very few hire labour.

Most farmers, $85 \%$, rely heavily on the natural forest and a few use gum plantation, $15 \%$, as source of firewood for tobacco curing. This entails that deforestation may persist in the future if no measures are put in place to reduce natural forests harvesting. The tree species that are mostly targeted for firewood are shown in Table 2, with Julbernardia globiflora (7\%), Brachystegia boehmii/spiciformis (23\%), and the combination of the two species dominating (70\%). There are fears that, if the trend persists, the species targeted may be extinct; hence there is a need to put some stringent measures to curb natural forests harvesting. The model presented by (3) is obtained by implementing binary logistic regression model and presents the effect of each variable to deforestation. Negative values show that the factor reduces deforestation by the coefficient of the factor expressed as a percentage. The positive value denoted the positive effect of each factor to deforestation. Consider

$$
\begin{aligned}
Y_{i}= & 0.57-1.10 x_{i 1}-2.09 x_{i 2}-2.64 x_{i 3}+0.09 x_{i 4} \\
& +0.15 x_{i 5}+0.09 x_{i 6}+0.92 x_{i 7} .
\end{aligned}
$$

The model findings are presented in Table 3 showing the beta coefficients, odds, and significance levels of each factor. Selling price of tobacco, farm experience, and agricultural training variables were found to be significant $(p<0.05)$, while sex, education level, tobacco yield, and the size of household variables were insignificant $(p>0.05)$ in contributing to natural forests harvesting.

The results indicated that three factors, namely, selling price of tobacco, farm experience, and agricultural training, have a significant influence on natural forest harvesting as a source of firewood for tobacco curing. All these factors negatively affect natural forests harvesting. When the selling price of tobacco increases, the harvesting of natural forests is reduced because the farmers are likely to have an increase in their income and prefer to use other firewood alternatives. What drives the farmers to use natural forests is maybe that the farmers do not afford other alternatives because of low incomes they get from selling their tobacco.

Agricultural training seems to influence natural forests harvesting negatively with $\beta=-2.64$. This means an increase in the number of agriculturally trained farmers; the level of harvesting of natural forests for tobacco curing may be reduced. The reduction of natural forests harvesting may be due to the knowledge the farmers can receive from the training that may include conservation measures and consequences of deforestation to the environment. On the other hand, untrained farmers (though some are educated) are not knowledgeable on issues to do with environmental sustainability. 
TABLE 3: Binary logistic regression model for factors influencing natural forest harvesting.

\begin{tabular}{|c|c|c|c|c|}
\hline Variables & Coefficients $(\beta)$ & SE & Significance & Odds ratio \\
\hline Agricultural training & -2.64 & 9704.98 & $0.04^{*}$ & 0.15 \\
\hline Selling price of tobacco & -2.09 & 0.87 & $0.02^{*}$ & 0.52 \\
\hline Farm experience & -1.10 & 9704.98 & $0.03^{*}$ & 0.23 \\
\hline Sex & 0.09 & 2.47 & 0.72 & 2.40 \\
\hline Education level & 0.92 & 1.01 & 0.36 & 2.51 \\
\hline Tobacco yield per hectare & 0.09 & 0.10 & 0.37 & 1.09 \\
\hline Size of the household & 0.15 & 0.72 & 0.83 & 1.17 \\
\hline Constant & 0.57 & 9704.98 & 1.00 & 1.18 \\
\hline
\end{tabular}

${ }^{*}$ Statistical significance at $5 \%$ level.

Farmers with advanced level of agricultural training are equipped with knowledge of conservation measures and impacts of certain agricultural activities to the environment. This may lead to reduction of them relying on natural forests as a source of firewood for tobacco curing. The farmers who are trained are likely to implement measures they gained from the training and this may result in them desisting from natural resource exploitation. Farmers who are not agriculturally trained are not very knowledgeable of environmental conservation and possible future consequences resulting from tobacco production.

The selling price of tobacco affect natural forests harvesting negatively with $\beta=-2.07$. This entails that when tobacco selling price decreases the farmers are likely to harvest more quantities of firewood sourced from natural forests. The reason might be that the farmers' disposable income is reduced such that the farmer cannot afford using other substitutes of firewood for curing tobacco such as coal and gum trees. An increase in the disposable income may lead the farmers, in future, to likely use other sources of firewood. since the farmers may afford to use other alternative sources. In addition to tobacco selling price, experience of the farmer also influence the harvesting of natural forests negatively $(p=0.03)$. Due to increase in the years of experience, the farmers are likely to reduce reliance on natural forests to obtain firewood for curing tobacco. The level of preparedness for tobacco production is high for experienced farmers and they tend to conserve the environment through switching to other sources of fuel instead of firewood. The farmers are knowledgeable on the impacts and government policies, such as penalties and taxes, for exploiting the natural forests. In contrast, the less experienced farmers are likely to increase natural forests depletion as they are not or less aware of environmental sustainability problems and solutions. Such farmers concentrate more on production of tobacco relying more on firewood which is cheap in order to maximise their income from tobacco production.

Sex, size of the household, tobacco yield, and level of education were insignificant in explaining the variations in the harvesting of natural forests. These factors are important in the model though their contributions to natural forests harvesting are negligible. This is contrary to the findings by Mkanta and Chimtembo [18] that family size has an influence to human labour. Mkanta and Kamuzora [19] postulated that larger sized households are less poor than those with smaller sizes. The difference in gender does not influence natural forests harvesting. Being a male or female does not hinder harvesting of natural forests. This could be because the natural forests are accessible to both males and females such that there are equal chances of cutting down the trees. Level of education, other than agricultural training, insignificantly contribute to natural forests harvesting.

The behaviour of a farmer with or without education is the same in terms of natural forests harvesting. This is in contrast with the level of agricultural training. Tobacco yield is insignificant in explaining the harvesting of natural forests by smallholder tobacco farmers. The reason may be that whether tobacco yields increase that does not necessarily mean that firewood demand increases significantly. Increased or decreased tobacco yield will not affect the barn capacity meaning that the quantity of firewood required per barn remains the same.

It has been noted that most of the farmers are aware of the environmental consequences caused by the production of tobacco in the smallholder sector. However, there is a need for the enforcement of the environmental policy measures in the areas where tobacco production is taking place as the major agricultural activity. There is also the need for penalties or fees the farmers must pay for exploiting the environment. Coal must be available and other alternatives for curing tobacco to the smallholder farmers at affordable prices.

There is the need to conserve the environment at the same time producing more of tobacco which contributes much on the Zimbabwean economy in terms of foreign currency earnings. The results from the study may be used in environmental policy, planning, and implementation. This may lead to the protection of the environment and natural resources from being overexploited at the same time increasing the generation of foreign currency through smallholder tobacco production. It is recommended that a policy be put in place by the Ministry of Agriculture, Mechanisation, and Irrigation Development in collaboration with the Environmental Management Agency to set the forest harvesting limit tallying with the maximum sustainable yield (MSY). The MSY is the yield that allows regrowth such that any yield beyond this point tends to affect negatively the environment.

The government must provide coal subsidies to the smallholder tobacco farmers and try to avail the needed quantities to farmers for tobacco curing. This can reduce pressure on natural forests, boost tobacco production (a major foreign 
currency earner), and conserve the environment for the future generations. In addition, the policies governing the use of natural resources through spot penalties, taxes, and fees must be channeled towards environment protection and conservation. It is highly recommended that fees/charges for smallholder tobacco production have to be channelled towards managing the environment.

\section{Conclusion and Recommendations}

The study results have shown that agricultural training, farm experience, and selling price of tobacco significantly affect harvesting of natural forests. A significant number of farmers rely heavily on natural forests for curing of tobacco. This calls for measures to be put in place by the policy makers to protect the environment from being degraded with time. More farmers are likely to venture into growing this crop as a result of farmer anticipation of high selling price of the crop at the market. This may put more pressure on the natural forest. There is a need for further research that develops an econometric model that can be used to determine the maximum sustainable yield of natural forest harvesting for the farmers either per district or per province. This further gives the guideline on the charges or fees to be paid by the farmer who uses natural forests for other different uses, that is, cooking, timber, and tobacco curing. The study must also project the future management levels of the natural forests based on the previous years and the current and future trends.

\section{Conflict of Interests}

The authors declare that there is no conflict of interests regarding the publication of this paper.

\section{References}

[1] M. Rukuni and C. K. Eicher, Zimbabwe's Agricultural Evolution, University of Zimbabwe, Harare, Zimbabwe, 1994.

[2] J. C. Keyser, "The costs and profitability of tobacco compared to other crops in Zimbabwe," Health, Nutrition and Population (HNP) Discussion Paper 1, Economics of Tobacco Control, World Bank, Washington, DC, USA, 2002.

[3] D. Pearce and K. Brown, "Saving the world tropical forests," in The Causes of Tropical Deforestation. The Economics and Statistical Analysis of Factors Giving Rise to the Loss of the Tropical Forest, pp. 2-26, UCL Press, 1994.

[4] J. K. A. Benhin, "Agriculture and deforestation in the tropics: a critical theoretical and empirical review," Ambio, vol. 35, no. 1, pp. 9-16, 2006.

[5] A. F. Ibimilua, "Appraisal of the causes and consequences of human induced deforestation in Ekiti State, Nigeria," Journal of Sustainable Development in Africa, vol. 14, no. 3, pp. 37-52, 2012.

[6] R. M. Hassan and G. Hertzler, "Deforestation from the overexploitation of wood resources as a cooking fuel: a dynamic approach to pricing energy resources in Sudan," Energy Economics, vol. 10, no. 2, pp. 163-168, 1988.

[7] World Bank, "Poverty and vulnerability assessment," Tech. Rep., World Bank, Washington, DC, USA, 1984.
[8] J. Lightwood, D. Collins, H. Lapsley, and T. E. Novotny, Estimating the Cost of Tobacco Use, Oxford University Press, New York, NY, USA, 2000.

[9] J. M. Abdallah, B. Mbilinyi, and Y. N. Ngaga, "Impact of fluecured Virginia on Miombo woodland: a case of small-scale flue-cured Virginia production in Iringa region, Tanzania," Discovery Innovations, vol. 19, no. 1-2, pp. S92-S106, 2007.

[10] M. G. Maiangwa, "Fuelwood markets in Sub Saharan Africa: factors which impede, and incentives which will accelerate their development," Production Agriculture and Technology, vol. 6, no. 1, pp. 36-48, 2010.

[11] International Tobacco Growers' Association, "The use of wood fuel for curing tobacco," Report, International Tobacco Growers' Association (ITGA), East Grinstead, Uk, 1996.

[12] I. I. Goll, B. Nick, J. Li, J. McKay, and S. John, "Analysis on the causes of deforestation and forest degradation in liberia: application of the DPSIR framework," Research Journal of Agriculture and Forestry Sciences, vol. 2, no. 3, pp. 20-30, 2014.

[13] T. Bensel, "Fuelwood, deforestation, and land degradation: 10 years of evidence from Cebu province, the Philippines," Land Degradation \& Development, vol. 19, no. 6, pp. 587-605, 2008.

[14] J. Madeley, “The evil weed, the observer," in Proceedings of the 5th World Conference on Smoking and Health, London, UK, 1993.

[15] J. T. Chipika and G. Kowero, "Deforestation of woodlands in communal areas of Zimbabwe: is it due to agricultural policies?" Agriculture, Ecosystems and Environment, vol. 79, no. 2-3, pp. 175-185, 2000.

[16] G. Adu, G. Marbuah, and J. T. Mensah, "Contribution of agriculture to deforestation in the tropics: a theoretical investigation," African Review of Economics and Finance, vol. 3, no. 2, pp. 1-12, 2012.

[17] N. Jules, Regenerating Agriculture: Policies and Practice for Sustainability and Self-Reliance, Earth Scan Publications, London, UK, 2nd edition, 1996.

[18] W. N. Mkanta and M. M. B. Chimtembo, "Towards natural resource accounting in Tanzania: a study on the contribution of natural income," CEEPA Discussion Paper 2, CEEPA, Dar es Salaam, Tanzania, 2002.

[19] W. N. Mkanta and C. L. Kamuzora, "Poverty and household size in Tanzania: multiple responses to population pressure," Research Report 2001.4, Research on Poverty Alleviation (REPOA), 2000. 


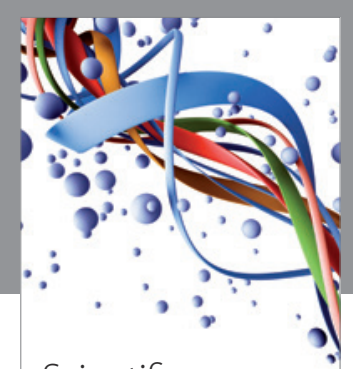

Scientifica
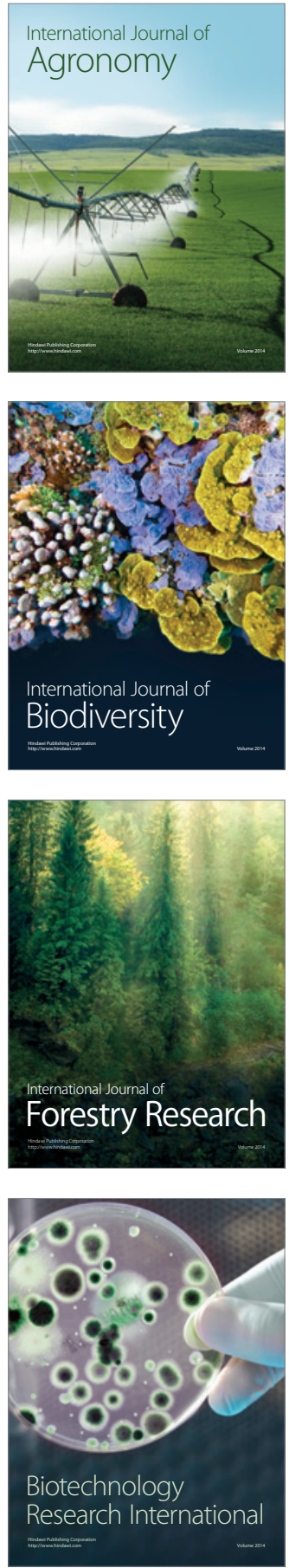
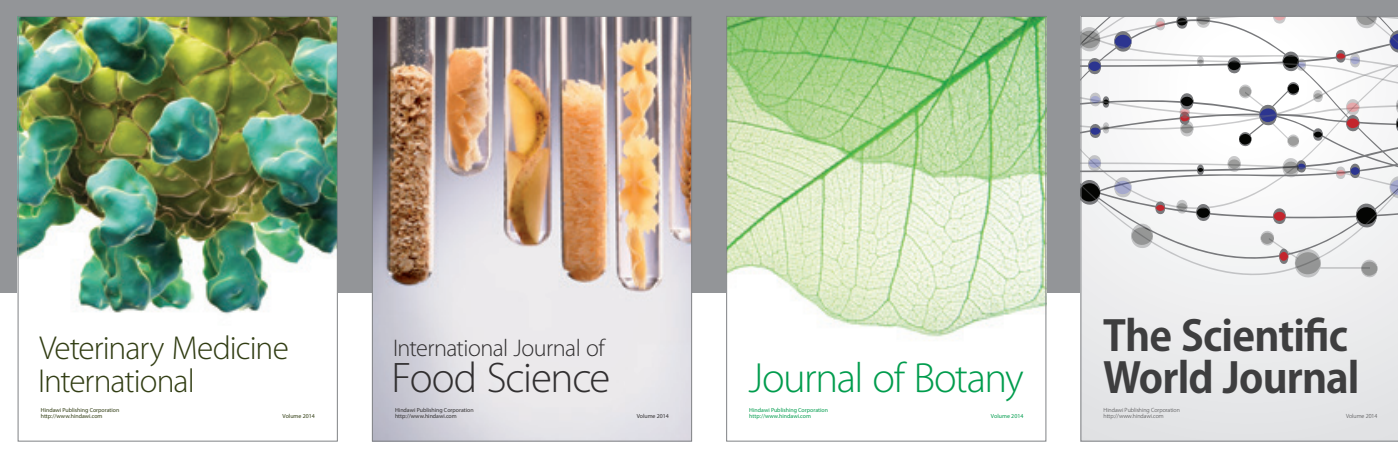

The Scientific

\section{World Journal}

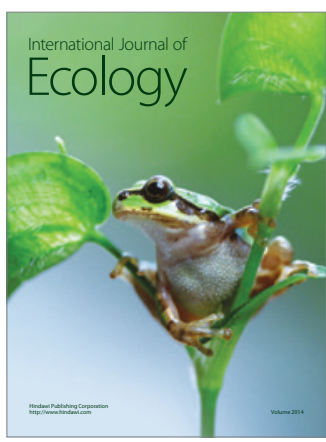

\section{Hindawi}

Submit your manuscripts at

http://www.hindawi.com
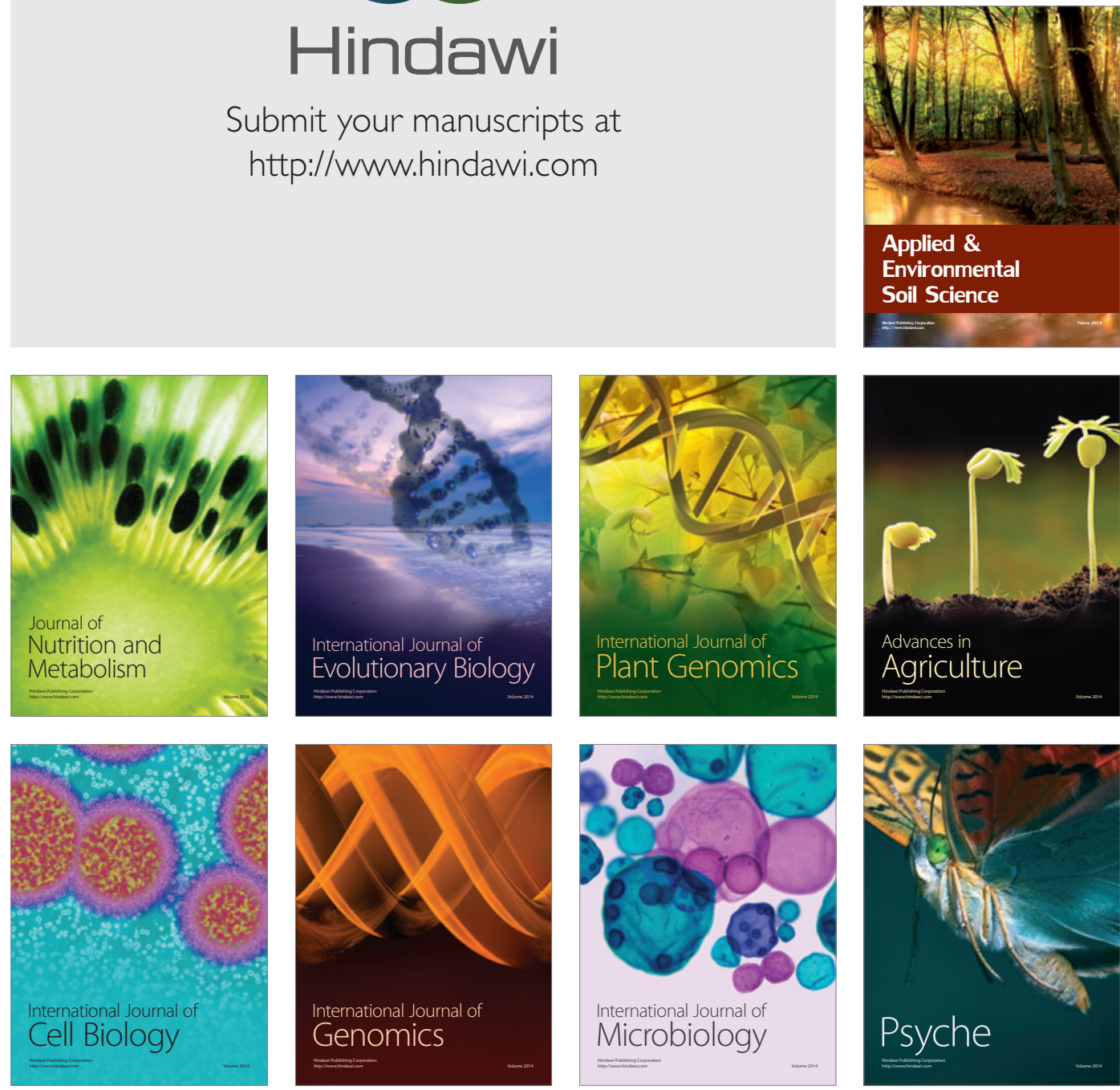
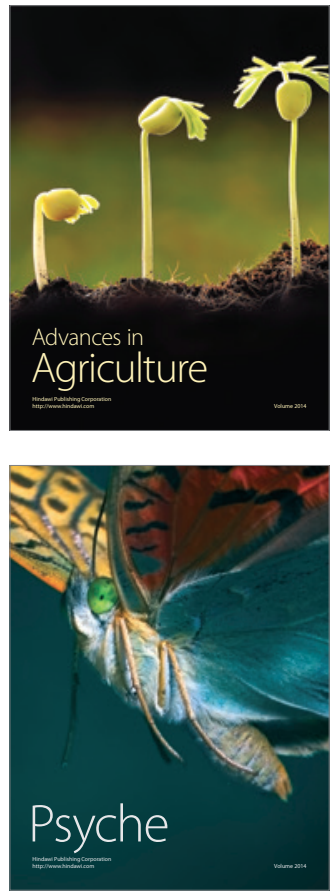